\title{
Pain Assessment
}

National Cancer Institute

\section{Source}

National Cancer Institute. Pain Assessment. NCI Thesaurus. Code C20992.

The evaluation of pain complaints. Measurements should be objective on the part of the practitioner, based on subjective information from the patient. Measurements may also be indirect, by such assessments as respiratory rate and effort, withdrawal, guarding, or other appropriate assessment techniques. 